\title{
Differential Expression of Gluconeogenic Enzymes in Early- and Late- Stage Diabetes: The Effect of Citrullus Colocynthis Seed Extract on Hyperglycemia and Hyperlipidemia
}

\section{Arezoo Afshari}

Tehran University of Medical Sciences

Fouzieh Salimi

Tehran University of Medical Sciences

\section{Masumeh Babaie}

University of Tehran

\section{Salar Bakhtiyari}

Ilam University of Medical Sciences

\section{Gholamreza Hassanzadeh}

Tehran University of Medical Sciences

\section{Maryam Shabani}

Tehran University of Medical Sciences

Azin Nowrouzi ( $\nabla$ anowrouzi@tums.ac.ir)

Tehran University of Medical Sciences https://orcid.org/0000-0003-1275-016X

\section{Research}

Keywords: Diabetes mellitus, Gluconeogenesis, Citrullus colocynthis Schrad, Hepatosteatosis, Glyceroneogenesis

Posted Date: May 29th, 2020

DOI: https://doi.org/10.21203/rs.3.rs-29655/v1

License: (c) (i) This work is licensed under a Creative Commons Attribution 4.0 International License. Read Full License 


\section{Abstract}

Background: The extent of metabolic disruption and the usefulness of drugs and supplements, such as medicinal plants, in patients with diabetes may be impacted by the severity of the disease.

Method: Nicotinamide + STZ together and STZ alone were used to induce early- and late-stage diabetes type 2 (ET2D and LT2D, respectively) in rats. Glucose tolerance test (GTT) was performed because the stage of disease was considered compatible with the magnitude of deviation from normal glucose tolerance test (GTT), as well as the level of FBS. Three main groups of the study were nondiabetic, early-stage diabetic, and late-stage diabetic rats. Each group was divided into two sub-groups, one of which received Citrullus colocynthis seed aqueous extract (CCAE, 90mg/kg BW) for 28 days. Weekly FBS and body weights were recorded during the study. At the end of 28 days, the serum levels of ALT, AST, ALP, TG, urea, creatinine, uric acid, cholesterol, HDL, LDL, c-peptide, and HbA1c were measured; the hepatic mRNA expression of several enzymes of glucose and fat metabolic pathways were also determined by Real-Time PCR. The accumulation of fat in the hepatic tissue was visualized by measuring the TG content and by H\&E and Oil-Red staining and the degree of oxidative stress was measured by protein carbonyl content (PCC).

Results: The LT2D rats showed maximal deviations from normal GTT. GTT for control and ET2D rats were similar, yet the area under curve (AUC) for ET2D rats was significantly higher. Urea, ALT, and ALP levels were high in diabetic rats compared to control and significantly different from each other.Serum TG dropped and ALT, ALP, HDL and LDL significantly improved after treatment with CCAE. Different patterns of G6Pase and PEPCK expression in ET2D and LT2D suggested their similarity to short- and long-term fasting states, respectively. While the reduction of FBS levels in ET2D could be explained by an inhibition of G6Pase expression and therefore glycogenolysis, the level of PEPCK expression was not significantly lowered by CCAE in LT2D. H\&E staining of liver tissue showed steatoses of varying morphology in both ET2D and LT2D rats. CCAE led to up-regulated PPARa and down-regulated CPT1 expressions.

Conclusion: As PEPCK activity is necessary for the continuation of the TG/FA cycle during fasting, it is possible that in LT2D, CCAE directed the PEPCK activity more towards glyceroneogenesis than gluconeogenesis to ensure the persistence of the TG/FA cycle. The enhanced glyceroneogenesis together with an up-regulated PPARa expression and down-regulated CPT1 expression probably led to lower blood and hepatic TG. More research is needed to establish the effect of CCAE on PEPCK expression and its course of activity.

\section{Introduction}

Diabetes type 2 (T2D) is the most prevalent type of diabetes worldwide. Patients are diagnosed with T2D when their blood glucose levelsincreaseafter a mealorwhenhungry. All major classes of approved pharmaceuticals currently used to treat diabetes are purified compounds [1]. Every so often, patients and the professionals turn to traditional medicines not only to avoid the drug-related side effects,such ashypoglycemia, nausea, vomiting, bloating, diarrhea or constipation but also to take advantage of their low costs and easy availability. Due to having several active components in naturally balanced proportions all in one pot, medicinal plants act simultaneously on multiple metabolic pathways to intelligently reestablish their lost harmony. Medicinal plants with sugar lowering properties are presumed to exert their antidiabetic activity via a variety of mechanisms, such as inhibition of intestinal glucose absorption, suppression of hepatic glucose production, induction of pancreatic insulin secretion, promotion of peripheral tissue (adipose and muscle) glucose uptake, and/or amelioration of oxidative stress [2] but the capacity of medicinal plants to regulate gene expression have remained largely unexplored.

Citrullus colocynthisSchrad. (C. colocynthis), with many common names including bitterapple, bitterwatermelon, or foxmelon,belongs tofamilyCucurbitaceae and grows intropicaland desert areas in Asia, Africa, andthe Mediterraneanregion. In rural areas, it is used as laxativeandinsecticide [3]. Several parts of $C$. colocynthis, including the 
pulp, rind, and seeds are popular for their hypoglycemic property. C. colocynthiscontains terpenes, flavonoids, alkaloids, glycosides, and saponins [4]. The seedsarerich infatty acids,such asmyristic, stearic, oleic, linoleicandlinolenic acids; essential amino acids, such asarginine, tryptophan, methionine; vitamins, such as B1, B2,andB3; andminerals, such as Ca, $\mathrm{Mg}, \mathrm{Mn}, \mathrm{K}, \mathrm{P}, \mathrm{Fe}$ and $\mathrm{Zn}$ [3]. Toxic effects of $C$. colocynthis have been also reported [5-8].

STZ is commonly used to induce late-stage T2D (analogous to uncontrolled T1D) in experimental animals. When STZ is combined with niacinamide (NIA), a stable non-obese version of T2D is created in which the pancreatic b-cells are only moderately destroyed $[9,10]$. These distinct types of STZ- and STZ/NIA-induced diabetes models display different degrees of hyperglycemia, dyslipidemia, and insulin resistance; and coping with them may require different treatment modalities.

As T2D is characterized by a dysfunction of enzymes involved in hepatic glucose and fat metabolism, we created mild and severe models of diabetes in rats, which we called early- (ET2D) and late-stage (LT2D) diabetes. We aimed to investigate the effects of the aqueous seed extract of $C$. colocynthis (which we called CCAE) on the mRNA expression of some of the rate-limiting enzymes in sugar metabolism, (gluconeogenesis pathway) including glucose 6-phosphatase (G6Pase) and phosphoenolpyruvate carboxykinase (PEPCK), and lipid metabolism, including insulin-dependent sterol regulatory element-binding protein-1c (SREBP-1c, a regulator of hepatic DNL), acetyl-CoA carboxylase (ACC, the regulator of FA synthesis and degradation), fatty acid synthase (FAS, the regulator of FA synthesis), peroxisome proliferatoractivated receptor alpha (PPARa, the regulator of b-oxidation) and carnitine palmitoyltransferase I (CPT1, a regulator of boxidation).

The differential expression levels of PEPCK and G6Pase in the mild and advanced stages of diabetes suggested that earlystage diabetes is similar to short-term fasting; late-stage diabetes resembles long-term fasting. The aqueous seed extract of $C$. colocynthis may regulate gene expression and determine the course or preference of enzyme action.

\section{Materials And Methods}

\section{Preparation of aqueous extract of $C$. colocynthis seed (CCAE)}

Bitter apple fruitwas collectedfrom the Saleh Abadregionof llam province, Iran, and authenticated by Faculty of Pharmacy; Tehran University of Medical Sciences (TUMS), with a voucher number PMP-648. The powdered seeds were soaked in distilled water $(100 \mathrm{~g} / \mathrm{l})$ and refluxed for $20 \mathrm{~min}$ in a water bath $\left(80^{\circ} \mathrm{C}\right)$. The cooled, vacuum filtered extract was concentrated by rotary evaporator before lyophilization (EYELA Freeze dryer FD-1, Japan).

\section{HPLC pattern of CCAE}

A $5 \mu \mathrm{l}$ sample of CCAE [ $4.0 \mathrm{mg}$ of the lyophilized substance dissolved in $500 \mu \mathrm{l}$ of HPLC grade water and filtered using a $0.45 \mu \mathrm{m} 13 \mathrm{~mm}$ syringe filter (Waters, USA)] was injected into an HPLC system (PLATIN blue, Knauer, Germany) equipped with UV-Vis detector. The separation was achieved at a flow rate of $1 \mathrm{ml} / \mathrm{min}$ at $280 \mathrm{~nm}$ on a Eurospher II 100-3 C18 column $(5 \mu \mathrm{m} ; 100 \times 3 \mathrm{~mm})$. The mobile phase consisted of $A, 1 \%$ acetic acid in water, $\mathrm{B}: 1 \%$ acetic acid in acetonitrile; gradient program: $A: 100 \%$ ( $0 \rightarrow 5 \mathrm{~min}), 100 \rightarrow 30 \%(5 \rightarrow 30 \mathrm{~min}), 30 \%(30 \rightarrow 35 \mathrm{~min})$, and $30 \rightarrow 100 \%(35 \rightarrow 45 \mathrm{~min})$.

\section{Animals}

Seven weeks old Male Wistar-Albino rats were maintained in an animal room $\left(22 \pm 2^{\circ} \mathrm{C}\right)$, with $12 \mathrm{~h}$ light-dark cycle and fed with normal rat chow diet and water ad libitum and cared for according to the guidelines for use of laboratory animals. All the animal experiments were approved by the ethical committee of Tehran University of Medical Sciences. 


\section{Diabetes induction}

After an overnight $(8 \mathrm{~h})$ fasting, the rats destined for LT2D and ET2D groups were injected with STZ or STZ + niacinamide (NIA), respectively (Sigma-Aldrich Co.; St. Louis, MO). The dose of STZ was $55 \mathrm{mg} / \mathrm{kg}$ body weight (B.W.) in Experiment-1; it was $65 \mathrm{mg} / \mathrm{kg}$ b.w. in the Experiment-2, as explained below. Both STZ and NIA were freshly prepared in $0.3 \mathrm{ml}$ cold normal saline and i.p. injected with insulin needles. NIA (200 mg/kg B.W.) was injected 15 min after STZ administration. Diabetes was confirmed by measuring glucose levels in peripheral blood obtained from the tail vein at days 4 and 10 after diabetes induction (GlucoSure STAR, ApexBio, Taiwan). Normal saline was injected into rats of the control group. STZinjected rats with fasting blood sugar (FBS) above $300 \mathrm{mg} / \mathrm{dl}$ on both occasions (day 4 and day 10) were considered as LT2D rats, and NIA/STZ-injected rats with stable FBS ranging between 140 and 220mg/dl were considered as ET2D [11].

\section{Experiment 1. Short-term experimental process(120 min IPGTT) for selection of CCAE dosage}

LT2D and ET2D were induced in twenty rats (average mass of 100 to $160 \mathrm{~g}$ ), with 10 rats in each group. Only, 3 of the STZinjected rats and 7 of the NIA/STZ-injected rats developed the corresponding types of diabetes, respectively. After measuring FBS in the overnight fasted rats, IPGTT was performed in two representative diabetic rats from each group. Glucose (2 g/kg b.w.) was coadministered into separate rats, with CCAE (the dose was either $90 \mathrm{mg} / \mathrm{kg} \mathrm{b.w.} \mathrm{or} 110 \mathrm{mg} / \mathrm{kg}$ b.w.) or metformin (100 mg/kg b.w.). Bloodsugar was recordedat 30 min intervals in the tail blood. The purpose of this experiment was to select CCAE dosage but it also showed the short-term hypoglycemic effects of CCAE.

\section{Experiment 2. Long-term (28-day) experimental process to investigate the effects of CCAE on sugar and fat metabolism}

After the induction of ET2D and LT2D as above, 14 of 40(35\%) STZ-injected rats, and16 of 20 (80\%) NIA/STZ-injected ratsdeveloped LT2D and ET2D, respectively. Rats that did not become diabetic $(n=28)$, received a second injection of STZ (55mg/kgb.w.) of which 6 diedand8 did not develop diabetes, and the remaining14rats that developed LT2D (FBS above $300 \mathrm{mg} / \mathrm{dl}$ on day 4 and 10)were placed in the STZ (6) andCCAE-STZ(8) groups (Supplement 1, Fig. 1A).

\section{Evaluation of impaired glucose tolerance (IGT) using IPGTT}

To evaluate the status of glucose tolerance, we performed IPGTT on all the rats with ET2D and only 3 representative rats from LT2D in the same manner as above using only glucose without the drugs. The purpose was to prove that despite causing moderate increases in FBS, early-stage diabetes can give rise to significant IGT. Even so, 4 NIA/STZ-injected (ET2D) rats that had near-normal GTTwere excluded from the study. It took about 5 days to perform IPGTT on all the ET2D rats since the procedure required overnight fasted. This time plus the prior 10 days spent for the induction of diabetes and its approval made a total of 15 days.

\section{Treatment with CCAE (study groups)}

Fifteen days after induction of diabetes, we started the CCAE treatment with the selected dose of CCAE for half of the rats in each group. Finally, we ended up with 6 groups of rats including: Con $(n=4), \operatorname{CCAE}-\operatorname{Con}(n=4), N I A / S T Z(n=8)$, CCAENIA/STZ ( $n=8)$, STZ ( $n=12)$, CCAE-STZ ( $n=14$, were alive on day 28) (Supplement 1, Fig. 1A). The treatment lasted for 28 days. At the end ofeach week,FBS and body weightsweremeasured. The amount of CCAE for the rats' daily $(90 \mathrm{mg} / \mathrm{kg})$ injections was determined according to their weekly body weights. 


\section{Blood and liver tissue collection}

After 28 days of treatment,blood $(4-5 \mathrm{ml})$ was collected from the heart under anesthesia by ketamineandxylazine. A sample $(2.5 \mathrm{ml})$ of the collected blood from each animal was transferred into tubes containing ethylenediaminetetraacetic acid (EDTA, $3 \mathrm{mg} / \mathrm{ml}$ ) to be used for HbA1cdetermination. Sera were prepared from the remaining blood samples. After dissection, liver tissues were frozenin liquid nitrogen. All samples were stored at $-80^{\circ} \mathrm{C}$ until analysis.

\section{Blood biochemistry}

The concentration of AST, ALT, ALP, urea, creatinine, TG, cholesterol, LDL, and HDL was measured in the Diabetes Center of Shariati Hospital, Tehran, Iran, using the respective kits (Human diagnostics). The c-peptide concentration and percent HbA1cwere determined using a c-peptide kit (Biosystem, Spain) and Human/Rat/Mice c-peptide ELISA kit (BioVision, America), respectively.

\section{Real-time PCR}

Total RNA was extracted from frozen liver tissue and purified using Hybrid-R Blood RNA (GeneAll, South Korea) and RNA Riboclear (GeneAll, South Korea) kit, respectively. The quantity and quality of extracted RNA were inspected by spectroscopic absorption at $260 \mathrm{~nm}$ and electrophoresis, respectively. Reverse transcription (RT) was performed with the Revert Aid First Strand cDNA Synthesis kit (Takara, Japan). Real-time PCR was performed with Rotor-Gene Q (Qiagen, Germany) using SYBR Premix Ex Taq (Takara, Japan). Primer sequences used in this study are listed in Table1. The relative changes in gene expression were determined using the $\Delta \mathrm{C}_{\mathrm{t}}$ method and normalized against the housekeeping bactin expression. To be able to compare the expression of any certain gene in all groups relative to each other, the simultaneous RT-PCR for every gene and the reference actin was performed in groups of two or three that are: Con and CCAE-Con; Con, NIA/STZ, and STZ; Con, NIA/STZ, and CCAE-NIA/STZ; and Con, STZ, and CCAE-STZ. The data were merged together in one graph.

Table 1

Primer sequences

\begin{tabular}{|lll|}
\hline Gene & Forward & Reverse \\
\hline -Actin $\beta$ & 5'-GTCCACACCCGCCACC-3' & 5'-ACCCATACCCACCATCACAC-3' \\
\hline PPAR a & 5'-CCA GTA CTG CCG TTT CCA CA-3' & 5'-TCT GCC TTC AGT TTT GCT TTC TC-3' \\
\hline SREBP-1C & 5'-AAG CGC TAC CGT TCC TCT ATC-3' & 5'-TGT GCT GTA AGA AGC GGA TGT-3' \\
\hline FAS & 5'-AAG CAG GCA CAC ACA ATG GA-3' & 5'-CTC GGA ACC ACT CAC ACC C-3' \\
\hline ACC & 5'-GTT GGA CAA CGC CTT CAC AC-3' & 5'-TCG CAG AAG CAG CCC ATT AC-3' \\
\hline CPT1 & 5'-ATC CAC CAT TCC ACT CTG CTC-3' & 5'-ACC TTG AAG TAC CGC CCT CT -3' \\
\hline PEPCK & 5'-GCGACCGTCCCCTTTGCATCT-3' & 5'-CCACCAAACACTCCCCCTCCTCC-3' \\
\hline G6Pase & 5'-AAGTCCCTCACCCTCCCAAAAG-3' & 5'-AAGCAATGCTGTCACCTTCCC-3' \\
\hline
\end{tabular}

\section{Protein and PCC determination}

A sample of the frozen liver (300mg) was homogenized in ice-cold PBS buffer ( $3 \mathrm{ml}, \mathrm{pH} 7.4)$ containing PMSF (5 mM) and anti-protease cocktail. After centrifugation at $1000 \mathrm{~g}$ at $4{ }^{\circ} \mathrm{C}$ to remove cell debris, the supernatants were collected, 
aliquoted and stored at $-80^{\circ} \mathrm{C}$ until used to measure protein concentration by BCA Protein Quantification kit (Pars-Tous, Iran) [12]and protein carbonyl content (PCC) by 2,4-dinitrophenylhydrazine (DNPH) reagent [13].

\section{Hepatic TG measurement}

A small piece of frozen liver ( 150 mg) was homogenized in $3 \mathrm{ml}$ of chloroform/methanol (2:1). The hepatic lipids were extracted, using the method suggested by [14]. TG content was measured by colorimetric-enzymatic kit (Parsazmun, Iran) and expressed as $\mathrm{mg} / \mathrm{g}$ tissue.

\section{Liver histology}

For hematoxylin and eosin (H\&E) staining, two samples from each frozen liver tissue were fixed in $10 \%$ formalin and embedded in paraffin. After cutting into $5 \mathrm{~mm}$ thickness, they were stained with H\&E. For Oil Red $O$ staining, two other samples from each group were cryostat sectioned. After immersing in $60 \%$ isopropanol for 5 min, sections were stained with freshly filtered Oil Red $O$ solution for $45 \mathrm{~min}$ at room temperature. The sections were washed with $60 \%$ isopropanol and then distilled water. The cryosections were then stained with hematoxylin. All samples were examined under an optical microscope.

\section{Statistical analyses}

Statistical analyses were performed using the GraphPad Prism software, version 8.2.1. Results are presented as mean \pm SEM unless otherwise stated. Statistical significance was defined as $p<0.05$.

\section{Results}

\section{Aqueous extract of the seeds from C. colocynthis (CCAE)}

We used the seeds because they are believed to be less toxic [15] and most effective in lowering blood sugar levels [16]. The aqueous extract may be assumed to keep the constituent compounds in their most natural shapes and has been reported to have better hypoglycemic effects than chloroform, ethanol, glycoside, and alkaloid extracts [17, 18]. HPLC profile of CCAE has been shown in Fig. 1.Further analysis of the extract components has not been performed.

\section{Selection of CCAE dosage using IPGTT}

According to the results, CCAE had an acute or short-term hypoglycemic effect in ET2D (Supplement1, Fig. 1B) consistent with Lahfa et al. [18]. Similar to Mojaz Dalfardi et al. [19], we noted that the hypoglycemic potency for $90 \mathrm{mg} / \mathrm{kg}$ of CCAE was comparable to $100 \mathrm{mg} / \mathrm{kg}$ of metformin. We selected this dosage (90 mg/kg of CCAE) for the daily treatment of rats during the long-term study.

\section{Evaluation of IGT by IPGTT}

To show the presence of impaired glucose tolerance, both models were exposed to IPGTT. As the presence of IGT in severe diabetes was predictable, fewer LT2D rats were exposed to IPGTT. FBS levels were not much higher than normal in rats with ET2D, and all seemed well enough to undergo IPGTT, which surprisingly revealed the presence of significant IGT in the early stages of diabetes. 


\section{FBS and body weights during a long-term experiment}

The average FBS levels were increased in both diabetic models (NIA/STZ group, $133.8 \pm 7.9 \mathrm{mg} / \mathrm{dl}, p=0.004$; STZ group, $453.0 \pm 41.7 \mathrm{mg} / \mathrm{dl}, p=0.001$; compared to Con, $95 \mathrm{mg} / \mathrm{dl} \pm 5.5$ ); and then lowered to near normal levels by CCAE in both groups ( $p>0.05$ vs. Con) (Fig. 2). The extract did not change the FBS in nondiabetic control (CCAE-Con) consistent with Lahfa et al. [18] but against Abdel-Hassan et al. [20] who reported the glucose-lowering effect of $C$. colocynthis in normal non-diabetic rabbits.

Body weights of control (Con and CCAE-Con) and ET2D (NIA/STZ and CCAE-NIA/STZ) rats increased significantly, during the study time (day 28 vs day 0: Con, $p=0.027$; CCAE-Con, $p=0.062 ; \mathrm{NIA} / \mathrm{STZ}, p=0.005$; and CCAE-NIA/STZ, $p=0.003$;). The weight loss in LT2D rats after diabetes induction ( $p<0.001$, day 0 vs. day -15$)$ continued further in the CCAE-treated groups (day 28 vs. day 0: CCAE-STZ, $p<0.001$; STZ, $p=0.538$ ) in disagreement with Benariba et al. who observed prevention of weight loss by $C$. colocynthis extract [21] and with Ahangarpour and Oroojan who reported a weight increase, in fructoseinduced insulin-resistant rat models [15]. Nevertheless, at day 28, the body weights of the treated groups, in the present study, were not significantly different from their corresponding controls (Fig. 2).

\section{C-peptide levels in serum}

Similar to a previous study [11], in the ET2D model the lower than normal levels of c-peptide indicated limited destruction of pancreatic beta cells; a complete lack of c-peptide in LT2D (STZ groups) showed a total absence of insulin in those rats. In contrast to several other studies [22, 23], our results suggested that treatment with CCAE for 28 days was not enough to cause an insulinotropic effect (Fig. 3).

\section{HbA1c levels in the blood}

The magnitude of elevation in blood $\mathrm{HbA} 1 \mathrm{c}$ levels is a function of both duration of exposure to high glucose levels and the actual concentration of blood glucose. Although it has been shown previously that the dried C. colocynthis fruit powder given to T2D patients can significantly reduce the $\mathrm{HbA} 1 \mathrm{c}$ levels $[24,25]$, the decrease of $\mathrm{HbA} 1 \mathrm{c}$ percentage in the CCAEtreated groups compared to their untreated counterparts was insignificant in the present study, perhaps due to the short treatment time (28 days) with the extract (Fig. 3).

\section{Blood biochemistry}

The major biochemical effect of CCAE was to lower serum TG levels in both diabetic models. TG levels rose in the sera of diabetic rats in agreement some reports [26, 27]; then significantly decreased towards normal in the treated groups (CCAENIA/STZ and CCAE-STZ groups vs. NIA/STZ and STZ groups: $p=0.0006$ and $p=0.0335$, respectively) consistent with other reports [28-32]. Oral administration of $70 \%$ alcohol extract of the pulp $(1.2 \mathrm{~g} / \mathrm{kg})$ in atherogenic rabbits was reported to significantly lower total cholesterol, triglycerides, and phospholipids in their liver, heart, and serum [33]. Concerning cholesterol levels in the blood, our results showed no significant difference between all groups $(p>0.9)$. Urea, creatinine, uric acid, and AST levels in blood did not change in diabetic groups, nor after treatment. Treatment with CCAE caused an increase in LDL levels in ET2D $(p=0.011)$ and a decrease in HDL levels in LT2D $(p<0.001)$. ALP activityincreased in the LT2D rats (STZ vs. Con, $p<0.01$ ) (Table 2). Treatment with CCAE has been shown, in previous studies, to improve some of the biomarkers $[34,35]$. 
Table 2

Fasting blood chemistry.

\begin{tabular}{|c|c|c|c|c|c|c|}
\hline & \multicolumn{2}{|c|}{ Control (not diabetic) } & \multicolumn{2}{|c|}{ Early Diabetes (ET2D) } & \multicolumn{2}{|c|}{ Late Diabetes (LT2D) } \\
\hline & Con & CCAE- Con & NIA/STZ & $\begin{array}{l}\text { CCAE- } \\
\text { NIA/STZ }\end{array}$ & STZ & CCAE -STZ \\
\hline Urea & $56.5 \pm 5.48$ & $49.33 \pm 3.75$ & $55.13 \pm 2.92^{\dagger}$ & $62.14 \pm 2.66$ & $94.50 \pm 4.88^{\dagger}$ & $95.42 \pm 4.83$ \\
\hline Creatinine & $0.47 \pm 0.06$ & $0.3 \pm 0$ & $0.33 \pm 0.01$ & $0.41 \pm 0.03$ & $0.39 \pm 0.03$ & $0.44 \pm 0.02$ \\
\hline Uric acid & $1.67 \pm 0.02$ & $1.83 \pm 0.08$ & $1.88 \pm 0.45$ & $3.31 \pm 0.86$ & $2.25 \pm 0.23$ & $2.36 \pm 0.18$ \\
\hline TG & $123.0 \pm 20.01$ & $168.0 \pm 30.61$ & $232.8 \pm 29.61$ & $90.71 \pm 6.40$ & $229.5 \pm 24.99$ & $136.91 \pm 29.74$ \\
\hline $\mathrm{TC}$ & $74.75 \pm 11.28$ & $89.33 \pm 13.32$ & $79.5 \pm 4.77$ & $79.14 \pm 4.17$ & $86.0 \pm 4.63$ & $79.08 \pm 6.58$ \\
\hline $\mathrm{HDL}$ & $37.5 \pm 5.29$ & $35.66 \pm 2.02$ & $37.87 \pm 2.99^{\dagger}$ & $38.85 \pm 2.53$ & $47.92 \pm 1.79^{\dagger}$ & $35.08 \pm 1.20$ \\
\hline LDL & $11.75 \pm 1.60$ & $26.67 \pm 6.43$ & $11.88 \pm 0.66$ & $19.71 \pm 1.58$ & $16.84 \pm 0.84$ & $20.75 \pm 1.14$ \\
\hline AST & $163.75 \pm 5.77$ & $143.33 \pm 36.44$ & $152.12 \pm 23.42$ & $170.28 \pm 17.38$ & $320.61 \pm 60.60$ & $171.08 \pm 13.99$ \\
\hline ALT & $62.25 \pm 9.98$ & $44.67 \pm 2.33$ & $50.0 \pm 5.97^{\dagger}$ & $46.14 \pm 3.13$ & $213.30 \pm 34.11^{\dagger}$ & $76.42 \pm 76.23$ \\
\hline ALP & $750.25 \pm 211.6$ & $717.33 \pm 41.39$ & $691.25 \pm 80.18^{\dagger}$ & $745 \pm 80.18$ & $3825.07 \pm 337.2^{\dagger}$ & $2572.58 \pm 273.5$ \\
\hline \multicolumn{7}{|c|}{$\begin{array}{l}\text { Data are presented as mean } \pm \text { SEM. Bold means statistically significant difference versus Con. Bold and italic shows } \\
\text { statistical significance versus untreated members of the same diabetic group. Statistical significance was determined } \\
\text { by non-parametric test followed by Kruskal-Wallistest in GraphPad Prism. †Shows parameters that were significantly } \\
\text { different in the blood of early and late diabetes group that is, ZTZ vs. NIA/STZ. All the variables are measured in mg/dl } \\
\text { except for enzyme activities that are reported in units/L. }\end{array}$} \\
\hline
\end{tabular}

\section{Hepatic PEPCK and G6Pase gene expression}

ET2D induction led to a $~ 4.5$-fold increase in the mRNA levels of G6Pase in NIA/STZ-group with a slight increase in PEPCK. On the contrary, LT2D induction was accompanied by a significant $~ 4.5$-fold increase in the mRNA levels of PEPCK in the STZ-group ( $p=0.007$ vs. Con) with onlya slight increase in G6Pase levels (Fig. 4). Treatment with CCAE led to significant suppression of G6Pase expression in ET2D ( $p=0.0055)$. But the suppression of PEPCK expression by CCAE in LT2D was not statistically meaningful $(p=0.6)$.A previous study has reported the suppression of hepatic $\mathrm{G} 6 \mathrm{Pase}$ and fructose 1, 6-bisphosphatase enzymatic activities in alloxan-induced rats, by a leaf suspension of $C$. colocynthis[36] but inhibition of PEPCK activity or its mRNA expression has not been reported.

\section{Hepatic fatty acid synthesis and oxidation pathways}

On day 28, the mRNA expression levels of SREBP-1c, ACC, FAS, and PPARa were significantly low in diabetic rats (STZ and NIA/STZ groups vs. Con, $p<0.05$ ) (Fig. 5) consistent with previous reports [37, 38]. Low ACC activity was detected by [30] in the sera of alloxan-induced diabetes which, in contrast to our results, increased after treatment with $C$. colocynthis.

Diabetes induction caused a reduction in PPARa levels in contrast to some [39] but in line with other reports that related it to such circumstances as a mitochondrial failure and oxidative stress [38], hyperglycemia [40] and low lipoprotein lipase $(\mathrm{LpL})$ activity [41]. After treatment with the extract, the mRNA levels of PPARa increased to near-normal levels in both CCAE-STZ and CCAE-NIA/STZ groups. Activation of hepatic expression of PPARa has been shown to ameliorate markers of diabetes, such as hepatic insulin resistance and steatosis [42, 43]. 
Despite the presence of a direct relationship between PPARa and CPT1 expressions [44], decreased expression of PPARa was accompanied by an increase in the mRNA levels of CPT1 in diabetic groups (1.5 and 2.0 folds in ET2D and LT2D, respectively) in agreement with other reports [45-48]. This up-regulation of CPT1 expression, in diabetes, stemmed from the diminished concentration of malonyl-CoA and lifting of its inhibitory effect on CPT1 [26, 48, 49]. The function of CPT1 is to mediate the transfer of FAs into mitochondria from cytosol; higher levels of CPT1 in STZ-rats implied a greater level of hepatic b-oxidation compared to NIA/STZ-rats. Treatment with CCAE lowered CPT1 mRNA levels back to near normal values $(p<0.001)$.

\section{Hepatic protein carbonylation (PCC) and TG concentration}

PCC levels did not increase significantly after diabetes induction (Fig. 6), in disagreement with [50]. Yet, upon treatment with CCAE, the decrease in PCC levels was significant. This antioxidant activity was in line with research that measured other markers of oxidative stress. For example, diabetic rats treated with various $C$. colocynthis extracts manifested decreased levels of TBARS, low expression of TNF- $a$ and IL-6, and increased enzymatic activities of SOD and CAT [51, 52].

The measurement of hepatic TG concentrations (Fig. 6) as well as H\&E and Oil-Red staining of the liver tissue samples (Fig. 7), showed high levels of fat in the untreated diabetic groups relative to Con which paralleled TG levels in serum (Fig. 6, Table 2). Unlike our results, some researchers noted a reduction of TG in the liver of STZ-induced rats which they attributed to increased hepatic b-oxidation [41] or declined rates of lipogenesis [37, 48]; yet others reported no change in the hepatic lipid content [49]. TG decreased significantly, in both serum and liver, after treatment with CCAE (Fig. 6, Table 2) in agreement with the reported effects of this plant against fatty liver [29].

\section{Liver histology}

Harmful changes in the structure of the liver, such as steatosis and fibrosis, are common findings in diabetes. Despite the high concentration of hepatic TG in both STZ and NIA/STZ rats (Fig. 6 and 7, Oil-Red $O$ staining), the absence of large lipid droplets (LDs) in the H\&E micrographs of liver from the STZ rats (in Fig. 7) implied differing architectures of LDs in different stages of diabetes. Congested central vein, dilatation of hepatic sinusoids (Fig. 7), fibrosis (Supplement 2), and excessive glycogen accumulation (Supplement 3) were other complications detected in livers of LT2D rats. Treatment with CCAE led to a reduction of hepatic lipid load in CCAE-NIA/STZ and CCAE-STZ groups (Fig. 6 and Fig. 7) in agreement with [53] but in contrast to [54] did not seem to alleviate the adverse changes in liver histology in CCAE-STZ.

\section{Discussion}

Previous studies have suggested that the hypoglycemic property of various $C$. colocynthis raw preparations stems from their ability to stimulate pancreatic insulin secretion[22, 23, 36, 55, 56]. In the present study, the CCAE extract effectively lowered the FBS and serum TG in both ET2D and LT2D rats (Fig. 2) even though the insulin levels did not seem to change during 28-day treatment.

Although the results of Oil-Red $O$ staining and the estimation of hepatic TG confirmed the presence of high levels of fat in the liver tissues of both ET2D and LT2D (Fig. 6 and 7), large LDs were evident only in the liver tissues of ET2D rats. Therefore, the types of fatty liver in ET2D and LT2D may be classified as macrovesicular steatosis (the formation of large LDs that displace the nucleus) and microvesicular steatosis (accumulation of small LDs with preserved cellular architecture), respectively [57].

Macrovesicular LDs grow during enhanced local TG synthesis [58]. In ET2D rats, the increased uptake of glucose into hepatocytes due to hyperglycemia-induced GLUT2 expression, and the activation of SREBP-1c by insulin (although insulin 
concentration was only about $40 \%$ of normal) would give rise to DNL [59]. While the newly synthesized hepatic fat and fat absorbed from food, called "new fat", is expected to act as a PPARa agonist and promote FA b-oxidation leading to the prevention of fat accumulation [60], the ongoing production of malonyl CoA by ACC (Fig. 5) and its inhibition of CPT1 may lead to the accumulation of macrovesicular type LDs in the liver of ET2D rats [61,62] (Fig. 7).

In LT2D there is a flow of "old fat" into hepatocytes, due to peripheral lipolysis. Unable to activate PPARa, and therefore mitochondrial b-oxidation [41, 60]"old fat" would accumulate in the liver. Meanwhile, the increased flow of FA into the mitochondria of hepatocytes, due to low ACC activity (Fig. 5), overwhelms the mitochondrial b-oxidation and activates the peroxisomal b-oxidation and cytochrome P450-dependent w-oxidation in the ER leading to ROS formation, lipid peroxidation, oxidative stress, inflammation, fibroblast accumulation, fibrosis, and liver injury, as seen in the liver of LT2D rats (Fig. 7) [38,63]. The arrangement of microvesicular LDs in the liver of LT2D rats may be the net effect of the high inflow of old-fat and disproportionate presence of oxidative stress [58] because despite the suppression of hepatic lipogenesis (DNL) in both diabetic models (Fig. 5), the ratio of b-oxidation to lipogenesis (taken as CPT1: SREBP1c ratio) was $>2.5$ times greater in LT2D (STZ group) compared to ET2D (NIA/STZ group) (Fig. 5) and also ROS level was high in LT2D livers (Fig. 6).

Autophagy is another relevant process that may affect the LD morphology. The presence of large LDs may be a sign of less damaged liver that is better capable of recovery. Larger LDs may be more readily available for fusion with lysosomes into autophagosomes, which are degraded to release the FAs that are then catabolized via b-oxidation [64-66]. In the insulin-resistant state, autophagy is greatly diminished. As we did not measure the markers of autophagy in the present study, we could not comment on it further.

In addition to FAs, glycerol-3-phosphate (G3P) is also required for the synthesis of TG within the hepatocytes. In the fed state, G3P is provided by glucose via glycolysis in both liver and adipose tissue. During the short-term fast, up to several hours, as in between meals, hepatic glycogenolysis maintains stable glucose levels in the blood [67]. The presence of low PEPCK expression and high G6Pase expression in the liver of ET2D rats (Fig. 4) along with relatively low glycogen in the liver of ET2D rats compared to LT2D rats (Supplement 3) suggest that early-stage diabetes is comparable to the short-term fasting state. Bandsma et al observed higher glycogen levels in liver upon 15 or $24 \mathrm{hr}$ fasting [68]in mice with PPARa deficiency. During the first hours of fasting, therefore, glucose released from glycogen stores, can continue to provide G3P via glycolysis.

During long periods of fasting (>12-14 h), exercise or advanced stages of diabetes, glucose homeostasis is achieved through the gluconeogenesis pathway and FFAs are released into the blood by lipolysis in WAT $[69,70]$. The majority of FFAs that are produced during lipolysis are re-esterified back to TGs in WAT without ever leaving the tissue. Some of the FFAs in blood serve as fuel for tissues such as the central nervous system and cardiac and skeletal muscles, as such or after conversion to ketone bodies in the liver. The leftover FFAs are re-esterified with G3P to TGs which normally leave the liver toward WAT in the form of VLDL but may accumulate in the liver to cause fatty liver [64]. The interconversion between FAs and TGs via "FAs + G3P ${ }^{\circledR}$ TG ${ }^{\circledR}$ FAs + Glycerol" is known as triglyceride/fatty acid (TG/FA) cycle [71]. It has been found recently that the needed G3P is provided by glyceroneogenesis which is a truncated form of gluconeogenesis pathway for the synthesis of G3P from non-carbohydrate precursors. WAT lacks glycerol kinase activity and depends on the glyceroneogenesis pathway for the de novo synthesis of G3P.Glyceroneogenesis is also the predominant source of hepatic G3P for VLDL synthesis despite the existence of significant glycerol kinase activity in the liver [72].

Interestingly, the rate controlling-step in both gluconeogenesis and glyceroneogenesis pathways is catalyzed by the cytoplasmic PEPCK (PEPCK-C) which catalyzes the decarboxylation and then phosphorylation of oxaloacetate to form phosphoenolpyruvate (PEP). PEP is then converted to dihydroxyacetone phosphate which can be partitioned between the paths toward the synthesis of glucose and conversion to G3P [73]. The expression of PEPCK-C is enhanced during long 
term fasting and carbohydrate-free diet (lack of glucose) to provide a source of carbon for gluconeogenesis and G3P for TG synthesis [74].

While high levels of PEPCK expression are associated with hyperglycemia, obesity, insulin resistance and even cancer [75, 76], the tissue-specific and whole-body knockout of PEPCK or its hypoactivity may lead to type 2 diabetes, insulin resistance, obesity, fatty liver, aging, lipodystrophy, and death [77]. Therefore, a well-balanced PEPCK activity is needed for appropriate serum sugar concentrations and a continuous intracellular (within WAT) and systemic (between WAT and liver) TG/FA cycle during fasting. The high expression of PEPCK in the liver of LT2D rats (Fig. 4) implied that the advanced-stage of diabetes (LT2D) was analogous to the long-term fasting state, and the presence of low levels of G6Pase may imply that most of the remaining PEPCK activity was directed more toward glyceroneogenesis than gluconeogenesis due to higher demand for TG/FA cycle under fasting (diabetic) condition. The TG/FA cycle creates a balance between lipolysis and re-esterification and to prevent an overt release of FA into the blood via increasing the uptake of TG into the adipose tissue [78]. It is therefore possible that CCAE spared a truly significantly suppression of PEPCK activity, in the present study, to allow the continuous operation of TG/FA cycle, which could partially accountfor the significant reduction of TG levels in the sera of LT2D rats (CCAE-STZ group) (Fig. 6).

CCAE's protection against hyperglycemia and hepatic lipid accumulation, in both ET2D and LT2D, can also be attributed to the activation of PPARa expression and the inhibition of the expression of CPT1 in the liver (Fig. 5).PPARa agonists are used as remedies for both hyperglycemia and steatohepatitis $[60,67,79]$.

\section{Conclusion}

The glucose tolerance was significantly impaired in both early-and late-stages of diabetes. $C$. colocynthis seed extract (CCAE) showed acute (in ET2D) and chronic (in both ET2D and LT2D) hypoglycemic effects. ET2D and LT2D seemed to be analogous to short- and long-term fasting states, respectively. CCAE affected both the sugar and fat metabolic pathways. It inhibited the expression of G6Pase, and therefore glycogenolysis, in the liver of ET2D rats, but its glucose-lowering activity in LT2D rats had little to do with the reduction of PEPCK expression; CCAE seemed to lower the rate of gluconeogenesis pathway mainly by rerouting PEPCK activity toward glyceroneogenesis. Low blood and hepatic TG could be the outcomes of the enhanced hepatic FA utilization, due to an up-regulated PPARa expression and down-regulated CPT1 expression, as well as the enhanced intracellular (within WAT) and systemic (between WAT and liver) TG/FA recycling due to an improved glyceroneogenesis.More study is needed to establish the effect of CCAE on PEPCK and the glyceroneogenic pathway.

\section{Abbreviations}

$\begin{array}{ll}\text { ACC } & \text { Acetyl-CoA carboxylase } \\ \text { ALP } & \text { Alkaline phosphatase } \\ \text { ALT } & \text { Alanine transaminase } \\ \text { AST } & \text { Aspartate transaminase } \\ \text { BCA } & \text { Bicinchoninic acid } \\ \text { CCAE } & \text { Citrullus colocythis aqueous extract } \\ \text { CPT1 } & \text { Carnitine palmitoyltransferase } \\ \text { DNL } & \text { De novo lipogenesis }\end{array}$




\begin{tabular}{|c|c|}
\hline DNPH & 2,4-dinitrophenylhydrazine \\
\hline ET2D & Early-stage type 2 diabetes \\
\hline FAS & Fatty acid synthase \\
\hline FBS & Fasting blood sugar \\
\hline G6Pase & Glucose 6-phosphatase \\
\hline IPGTT & Intra peritoneal glucose tolerance test \\
\hline HbA1c & Glycosylated hemoglobin \\
\hline HDL & High density lipoprotein \\
\hline I.P. & Intraperitoneal \\
\hline IGT & Impaired glucose tolerance \\
\hline IPGTT & Intraperitoneal glucose tolerance test \\
\hline LD & Lipid droplet \\
\hline LDL & Low density lipoprotein \\
\hline LT2D & Late-stage type 2 diabetes \\
\hline NIA & Niacinamide (nicotinamide) \\
\hline PCC & Protein carbonyl content \\
\hline PEPCK & Phophoenlpyruvate carboxykinase \\
\hline PMSF & Phenylmethylsulfonyl fluoride \\
\hline PPARa & Peroxisome proliferator-activated receptor alpha \\
\hline $\mathrm{RBC}$ & Red blood cell \\
\hline SREBP-1c & Sterol regulatory element binding protein- $1 \mathrm{c}$ \\
\hline STZ & Streptozotocin \\
\hline $\mathrm{T} 2 \mathrm{D}$ & Type 2 diabetes \\
\hline TG & Triacylglycerol \\
\hline TG/FA cycle & Triglyceride/fatty acid cycle \\
\hline WAT & White adipose tissue \\
\hline \multicolumn{2}{|c|}{ Declarations } \\
\hline
\end{tabular}




\section{Conflict of interest}

The authors declare no conflict of interest.

\section{Funding}

The financial support was provided by Tehran University of Medical Sciences and Health Services through Grants No. 9401-30-28678 and 95-04-30-33306.

\section{Author contribution}

AA: Investigation;FS: Investigation; MBK: Methodology; SB: Conceptualization, Statistical analysis; GH: Micrograph interpretation;MS: Methodology;AN: Conceptualization, Supervision, Writing-Reviewing and Editing.

\section{Acknowledgments}

We would like to thank the Histogenotech Research Laboratory, Tehran, Iran, for preparing and staining liver tissue sections.

\section{References}

1. Distefano JK, Watanabe RM. Pharmacogenetics of anti-diabetes drugs. Pharmaceuticals (Basel). 2010;3(8):2610-46.

2. El-Abhar HS, Schaalan MF. Phytotherapy in diabetes: Review on potential mechanistic perspectives. World J Diabetes. 2014;5(2):176-97.

3. Gurudeeban S, Satyavani K, Ramanathan T. Bitter Apple (Citrullus colocynthis): An overview of chemical composition and biomedical potentials. Asian J Plant Sci. 2010;9(7):394-401.

4. Rani A, Goyal A, Arora S. A brief review on Citrullus colocynthis- bitter Apple. Arch Curr Res Int. 2017;8(4):1-9.

5. Al-Yahya MA, AH AL-F, Adam SE. Preliminary toxicity study on the individual and combined effects of Citrullus colocynthis and Nerium oleander in rats. Fitoterapia. 2000;71(4):385-91.

6. Dehghani F, Panjehshahin MR. The toxic effect of alcoholic extract of Citrullus colocynthis on rat liver. Iranian Journal of Pharmacology \& Therapeutics. 2006;5:117-9.

7. Shafaei H, Rad JS, Delazar A, Behjati M. The effect of pulp and seed extract of Citrullus Colocynthis, as an antidaibetic medicinal herb, on hepatocytes glycogen stores in diabetic rabbits. Adv Biomed Res. 2014;3:258.

8. Soufane S, Bedda A, Mahdeb N, Bouzidi A. Acute toxicity study on Citrullus colocynthis fruit methanol extract in Albino rats. J Appl Pharm Sci. 2013;3(06):088-93.

9. Ghasemi A, Khalifi S, Jedi S. Streptozotocin-nicotinamide-induced rat model of type 2 diabetes (review). Acta Physiol Hung. 2014;101(4):408-20.

10. Kishore L, Kajal A, Kaur N. Role of nicotinamide in streptozotocin induced diabetes in animal models. J Endocrinol Thyroid Res. 2017;2(1):1-4.

11. Rezagholizadeh L, Pourfarjam Y, Nowrouzi A, Nakhjavani M, Meysamie A, Ziamajidi N, et al. Effect of Cichorium intybus L. on the expression of hepatic NF-kappaB and IKKbeta and serum TNF-alpha in STZ- and STZ+ niacinamideinduced diabetes in rats. Diabetol Metab Syndr. 2016;8:11. 
12. Olson BJSC, Markwell J. Assays for the determination of protein concentration. Assays for determination of protein concentration: John Wiley \& Sons, Inc; 2007. p. 14-7.

13. Reznick AZ, Packer L. Oxidative Damage to Proteins: Spectrophotometric method for carbonyl assay. Method Enzymol. 1994;233:357-63.

14. Folch J, Lees M, Sloane Stanley GH. A simple method for the isolation and purifcation of total lipides from animal tissues. J Biol Chem. 1957;226(1):497-509.

15. Ahangarpour A, Oroojan AA. Effect of crust and seed hydro-alcoholic and aqueous extracts and pulp hydro-alcoholic extract of Citrullus colocynthis on glucose, insulin and FIRI level in insulin resistant male rat's. Quarterly of Horizon of Medical Sciences. 2013;19(3):149-54.

16. Sebbagh N, Cruciani-Guglielmacci C, Ouali F, Berthault MF, Rouch C, Sari DC, et al. Comparative effects of Citrullus colocynthis, sunflower and olive oil-enriched diet in streptozotocin-induced diabetes in rats. Diabetes Metab. 2009;35(3):178-84.

17. Agarwal V, Sharma AK, Upadhyay A, Singh G, Gupta R. Hypoglycemic effects of Citrullus colocynthis roots. Acta Pol Pharm. 2012;69(1):75-9.

18. Lahfa FB, Azzi R, Mezouar D, R. Djaziri R. Hypoglycemic effect of Citrullus colocynthis extracts. Phytothérapie. 2017;15:50-6.

19. Mojaz Dalfardi N, Ghodrati Azadi H, Fathi Hafshjani B. Comparison of the effect of edible Citrullus colocynthis fruit powder with metformin on the level of blood glucose in streptozotocin-induced diabetic male rats. Quarterly of Horizon of Medical Sciences. 2015;21(1):7-12.

20. Abdel-Hassan IA, Abdel-Barry JA, Mohammeda ST. The hypoglycaemic and antihyperglycaemic effect of Citrullus colocynthis fruit aqueous extract in normal and alloxan diabetic rabbits. J Ethnopharmacol 2000;71:325-30.

21. Benariba N, Djaziri R, Zerriouh BH, Boucherit Z, Louchami K, Senner A, et al. Antihyperglycemic effect of Citrullus colocynthis seed aqueous extracts in streptozotocin-induced diabetic rats. Met Funct Res Diab. 2009;2:71-7.

22. Amin A, Tahir M, Lone KP. Effect of Citrullus colocynthis aqueous seed extract on beta cell regeneration and intra-islet vasculature in alloxan induced diabetic male albino rats. J Pak Med Assoc. 2017;67(5):715-21.

23. Benariba N, Djaziri R, Hupkens E, Louchami K, Malaisse WJ, Sener A. Insulinotropic action of Citrullus colocynthis seed extracts in rat pancreatic islets. Mol Med Rep. 2013;7(1):233-6.

24. Barghamdi B, Ghorat F, Asadollahi K, Sayehmiri K, Peyghambari R, Abangah G. Therapeutic effects of Citrullus colocynthis fruit in patients with type II diabetes: A clinical trial study. J Pharm Bioallied Sci. 2016;8(2):130-4.

25. Huseini HF, Darvishzadeh F, Heshmat R, Jafariazar Z, Raza M, Larijani B. The clinical investigation of Citrullus colocynthis (L.) schrad fruit in treatment of Type II diabetic patients: a randomized, double blind, placebo-controlled clinical trial. Phytother Res. 2009;23(8):1186-9.

26. Liu F, Xie M, Chen D, Li J, Ding W. Effect of V(IV)O(dipic-Cl)(H2O)2 on lipid metabolism disorders in the liver of STZinduced diabetic rats. J Diabetes Res. 2013;2013:956737.

27. Ohno T, Horio F, Tanaka S, Terada M, Namikawa T, Kitoh J. Fatty liver and hyperlipidemia in IDDM (insulin-dependent diabetes mellitus) of streptozotocin-treated shrews. Life sciences. 2000;66(2):125-31.

28. Dallak M. In vivo, hypolipidemic and antioxidant effects of Citrullus colocynthis pulp extract in alloxan-induced diabetic rats. Afr J Biotechnol. 2011;10(48):9898-903.

29. Esmail OEA. A possible protective effect of Citrullus colocynthis Melon against diabetes mellitus type 2 associated with non-alcoholic fatty liver syndrome in rats. J Am Sci 2012;8(8):1054-61.

30. Jeyanthi KA, Mary Violet Christy A. Hypolipidemic effect of Citrullus colocynthis seed powder in alloxan induced diabetic rats. J Int Dent Medical Res. 2009;2(3):105-9.

Page $14 / 25$ 
31. Rahbar AR, Nabipour I. The hypolipidemic effect of Citrullus colocynthis on patients with hyperlipidemia. Pak J Biol Sci. 2010;13(24):1202-7.

32. Zamani M, Rahimi AO, Mahdavi R, Nikbakhsh M, Jabbari MV, Rezazadeh H, et al. Assessment of anti-hyperlipidemic effect of Citrullus colocynthis. Revista Brasileira de Farmacognosia. 2007;17:492-6.

33. Daradka H, Almasad MM, Qazan W, El-Banna NM, Samara OH. Hypolipidaemic effects of Citrullus colocynthis L. in rabbits. Pak J Biol Sci. 2007;10(16):2768-71.

34. Al-Ghaithi F, El-Ridi MR, Adeghate E, Amiri MH. Biochemical effects of Citrullus colocynthis in normal and diabetic rats. Mol Cell Biochem. 2004;261(1-2):143-9.

35. Arkkila PE, Koskinen PJ, Kantola IM, Ronnemaa T, Seppanen E, Viikari JS. Diabetic complications are associated with liver enzyme activities in people with type 1 diabetes. Diabetes Res Clin Pract. 2001;52(2):113-8.

36. Gurudeeban S, Ramanathan T. Antidiabetic effect of Citrullus colocynthis in alloxan induceddiabetic rats. Inventi Rapid: Ethnopharmacology 2010;1(1):4 pages.

37. Shimomura I, Bashmakov Y, Ikemoto S, Horton JD, Brown MS, Goldstein JL. Insulin selectively increases SREBP-1C mRNA in the livers of rats with streptozotocin-induced diabetes. Proc Natl Acad Sci U S A. 1999;96(24):13656-61.

38. Ziamajidi N, Khaghani S, Hassanzadeh G, Vardasbi S, Ahmadian S, Nowrouzi A, et al. Amelioration by chicory seed extract of diabetes- and oleic acid-induced non-alcoholic fatty liver disease (NAFLD)/non-alcoholic steatohepatitis (NASH) via modulation of PPARalpha and SREBP-1. Food Chem Toxicol. 2013;58:198-209.

39. Im SS, Kim MY, Kwon SK, Kim TH, Bae JS, Kim H, et al. Peroxisome proliferator-activated receptor \{alpha\} is responsible for the up-regulation of hepatic glucose-6-phosphatase gene expression in fasting and db/db Mice. J Biol Chem. 2011;286(2):1157-64.

40. Zhou JY, Zhou SW, Zhang KB, Tang JL, Guang LX, Ying Y, et al. Chronic effects of berberine on blood, liver glucolipid metabolism and liver PPARs expression in diabetic hyperlipidemic rats. Biol Pharm Bull. 2008;31(6):1169-76.

41. Willecke F, Scerbo D, Nagareddy P, Obunike JC, Barrett TJ, Abdillahi ML, et al. Lipolysis, and not hepatic lipogenesis, is the primary modulator of triglyceride levels in streptozotocin-induced diabetic mice. Arterioscler Thromb Vasc Biol. 2015;35(1):102-10.

42. Chan SM, Sun RQ, Zeng XY, Choong ZH, Wang H, Watt MJ, et al. Activation of PPARalpha ameliorates hepatic insulin resistance and steatosis in high fructose-fed mice despite increased endoplasmic reticulum stress. Diabetes. 2013;62(6):2095-105.

43. Xu KZ-Y, Zhu C, Kim MS, Yamahara J, Li Y. Pomegranate flower ameliorates fatty liver in an animal model of type 2 diabetes and obesity. J Ethnopharmacol. 2009;123(2):280-7.

44. Song S, Attia RR, Connaughton S, Niesen MI, Ness GC, Elam MB, et al. Peroxisome proliferator activated receptor alpha (PPARalpha) and PPAR gamma coactivator (PGC-1alpha) induce carnitine palmitoyltransferase IA (CPT-1A) via independent gene elements. Mol Cell Endocrinol. 2010;325(1-2):54-63.

45. Zhang F, Xu X, Zhang Y, Zhou B, He Z, Zhai Q. Gene expression profile analysis of type 2 diabetic mouse liver. PLoS One. 2013;8(3):e57766.

46. Memon RA, Tecott LH, Nonogaki K, Beigneux A, Moser AH, Grunfeld CA, et al. Up-regulation of peroxisome proliferatoractivated receptors (PPARa) and PPAR-g messenger ribonucleic acid expression in the liver in murine obesity:

Troglitazone induces expression of PPARg-responsive adipose tissue-specific genes in the liver of obese diabetic mice. Endocrinology. 2000;141(11):4021-31.

47. Chiodi P. Diabetes mellitus: could the inhibition of a single enzyme (CPT-1) involved in the beta-oxidation process improve this complex Disease? Curr Res Diabetes Obes J. 2017;1(3).

48. Jourdan T, Djaouti L, Demizieux L, Gresti J, Verges B, Degrace P. Liver carbohydrate and lipid metabolism of insulindeficient mice is altered by trans-10, cis-12 conjugated linoleic acid. J Nutr. 2009;139(10):1901-7. 
49. Choi SH, Ginsberg HN. Increased very low density lipoprotein (VLDL) secretion, hepatic steatosis, and insulin resistance. Trends Endocrinol Metab. 2011;22:353-63.

50. Cumaoglu A, Cevik C, Rackova L, Ari N, Karasu C. Effects of antioxidant stobadine on protein carbonylation, advanced oxidation protein products and reductive capacity of liver in streptozotocin-diabetic rats: Role of oxidative/nitrosative stress. BioFactors. 2007;30:171-8.

51. Dallak M, Jaliah BI. Antioxidant activity of citrullus colocynthis pulp extract in the RBC's of alloxan-induced diabetic rats. Pak J Physiol. 2010;6(1):1-5.

52. Sanadgol N, Najafi S, Ghasemi LV, Motalleb G, Estakhr J. A study of the inhibitory effects of Citrullus colocynthis (CCT) using hydro-alcoholic extract on the expression of cytokines: TNF-a and IL-6 in high fat diet-fed mice towards a cure for diabetes mellitus. J Pharmacognosy and Phytother 2011;3(6):81-8.

53. Khalil M, Mohamed G, Dallak M, Al-Hashem F, Sakr H, Eid RA, et al. The effect of Citrullus colocynthis pulp extract on the liver of diabetic rats a light and scanning electron microscopic study. Am J Biochem Biotechnol 2010;6(3):155-63.

54. Oryan A, Hashemnia M, Hamidi AR, Mohammadalipour A. Effects of hydro-ethanol extract of Citrullus colocynthis on blood glucose levels and pathology of organs in alloxan-induced diabetic rats. Asian Pac J Trop Dis. 2014;4(2):12530 .

55. Ebrahimi E, Bahramzadeh S, Hashemitabar M, Mohammadzadeh G, Shirali S, Jodat J. Effect of hydroalcoholic leaves extract of Citrullus colocynthis on induction of insulin secretion from isolated rat islets of Langerhans. Asian Pac $\mathrm{J}$ Trop Dis. 2016;6(8):638-41.

56. Nmila R, Gross R, Rchid H, Roye M, Manteghetti M, Petit P, et al. Insulinotropic effect of Citrullus colocynthis fruit extracts. Planta Med. 2000;66(5):418-23.

57. Gluchowski NL, Becuwe M, Walther TC, Farese RV, Jr. Lipid droplets and liver disease: from basic biology to clinical implications. Nat Rev Gastroenterol Hepatol. 2017;14(6):343-55.

58. Wilfling F, Wang H, Haas JT, Krahmer N, Gould TJ, Uchida A, et al. Triacylglycerol synthesis enzymes mediate lipid droplet growth by relocalizing from the ER to lipid droplets. Dev Cell. 2013;24(4):384-99.

59. Matsuzaka T, Shimano H, Yahagi N, Amemiya-Kudo M, Okazaki H, Tamura Y, et al. Insulin-independent induction of sterol regulatory element-binding protein-1c expression in the livers of streptozotocin-treated mice. Diabetes. 2004;53(3):560-9.

60. Chakravarthy MV, Pan Z, Zhu Y, Tordjman K, Schneider JG, Coleman T, et al. "New" hepatic fat activates PPARalpha to maintain glucose, lipid, and cholesterol homeostasis. Cell Metab. 2005;1(5):309-22.

61. Park H, Kaushik VK, Constant S, Prentki M, Przybytkowski E, Ruderman NB, et al. Coordinate regulation of malonylCoA decarboxylase, sn-glycerol-3-phosphate acyltransferase, and acetyl-CoA carboxylase by AMP-activated protein kinase in rat tissues in response to exercise. J Biol Chem. 2002;277:32571-7.

62. Mashek DG. Hepatic fatty acid trafficking: multiple forks in the road. Adv Nutr. 2013;4(6):697-710.

63. Tang CC, Huang HP, Lee YJ, Tang YH, Wang CJ. Hepatoprotective effect of mulberry water extracts on ethanol-induced liver injury via anti-inflammation and inhibition of lipogenesis in C57BL/6J mice. Food Chem Toxicol. 2013;62:786-96.

64. Bechmann LP, Hannivoort RA, Gerken G, Hotamisligil GS, Trauner M, Canbay A. The interaction of hepatic lipid and glucose metabolism in liver diseases. J Hepatol. 2012;56(4):952-64.

65. Yan H, Gao YQ, Zhang Y, Wang H, Liu GS, Lei JY. Chlorogenic acid alleviates autophagy and insulin resistance by suppressing JNK pathway in a rat model of nonalcoholic fatty liver disease. J Biosci. 2018;43(2):287-94.

66. Allaire M, Rautou PE, Codogno P, Lotersztajn S. Autophagy in liver diseases: Time for translation? J Hepatol. 2019;70(5):985-98.

67. Peeters A, Baes M. Role of PPARalpha in hepatic carbohydrate metabolism. PPAR Res. 2010;2010. 
68. Bandsma RH, Van Dijk TH, Harmsel At A, Kok T, Reijngoud DJ, Staels B, et al. Hepatic de novo synthesis of glucose 6phosphate is not affected in peroxisome proliferator-activated receptor alpha-deficient mice but is preferentially directed toward hepatic glycogen stores after a short term fast. J Biol Chem. 2004;279(10):8930-7.

69. Weickert MO, Pfeiffer AF. Signalling mechanisms linking hepatic glucose and lipid metabolism. Diabetologia. 2006;49(8):1732-41.

70. Wang Y, Kwon H, Su X, Wondisford FE. Glycerol not lactate is the major net carbon source for gluconeogenesis in mice during both short and prolonged fasting. Mol Metab. 2020;31:36-44.

71. Reshef L, Olswang Y, Cassuto H, Blum B, Croniger CM, Kalhan SC, et al. Glyceroneogenesis and the triglyceride/fatty acid cycle. J Biol Chem. 2003;278(33):30413-6.

72. Beale EG, Antoine B, Forest C. Glyceroneogenesis in adipocytes: another textbook case. Trends Biochem Sci. 2003;28(8):402-3.

73. Yang J, Kalhan SC, Hanson RW. What is the metabolic role of phosphoenolpyruvate carboxykinase? J Biol Chem. 2009;284(40):27025-9.

74. Hanson RW, Reshef L. Glyceroneogenesis revisited. Biochimie. 2003;85(12):1199-205.

75. Grasmann G, Smolle E, Olschewski H, Leithner K. Gluconeogenesis in cancer cells - Repurposing of a starvationinduced metabolic pathway? Biochim Biophys Acta Rev Cancer. 2019;1872(1):24-36.

76. Burgess SC, He T, Yan Z, Lindner J, Sherry AD, Malloy CR, et al. Cytosolic phosphoenolpyruvate carboxykinase does not solely control the rate of hepatic gluconeogenesis in the intact mouse liver. Cell Metab. 2007;5(4):313-20.

77. Zhang J. Suppression of phosphoenolpyruvate carboxykinase gene expression by reduced endogenous glutathione level. BBA-MOL BASIS DIS. 2007;1772(10):1175-81.

78. Beale EG, Hammer RE, Antoine B, Forest C. Disregulated glyceroneogenesis: PCK1 as a candidate diabetes and obesity gene. Trends Endocrinol Metab. 2004;15(3):129-35.

79. Koh EH, Kim MS, Park JY, Kim HS, Youn JY, Park HS, et al. Peroxisome proliferator-activated receptor (PPAR)-a activation prevents diabetes in OLETF Rats. Diabetes 2003;52:2331-37.

\section{Figures}

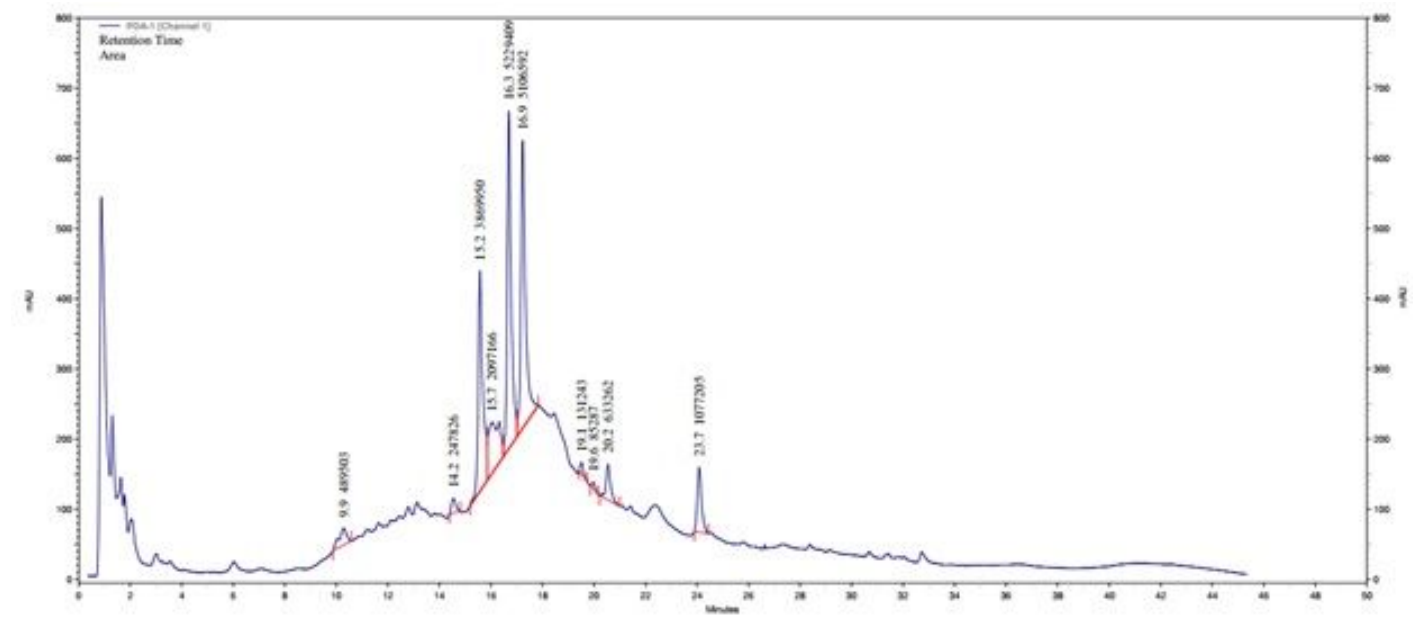

\section{Figure 1}

Typical HPLC chromatogram of CCAE. 

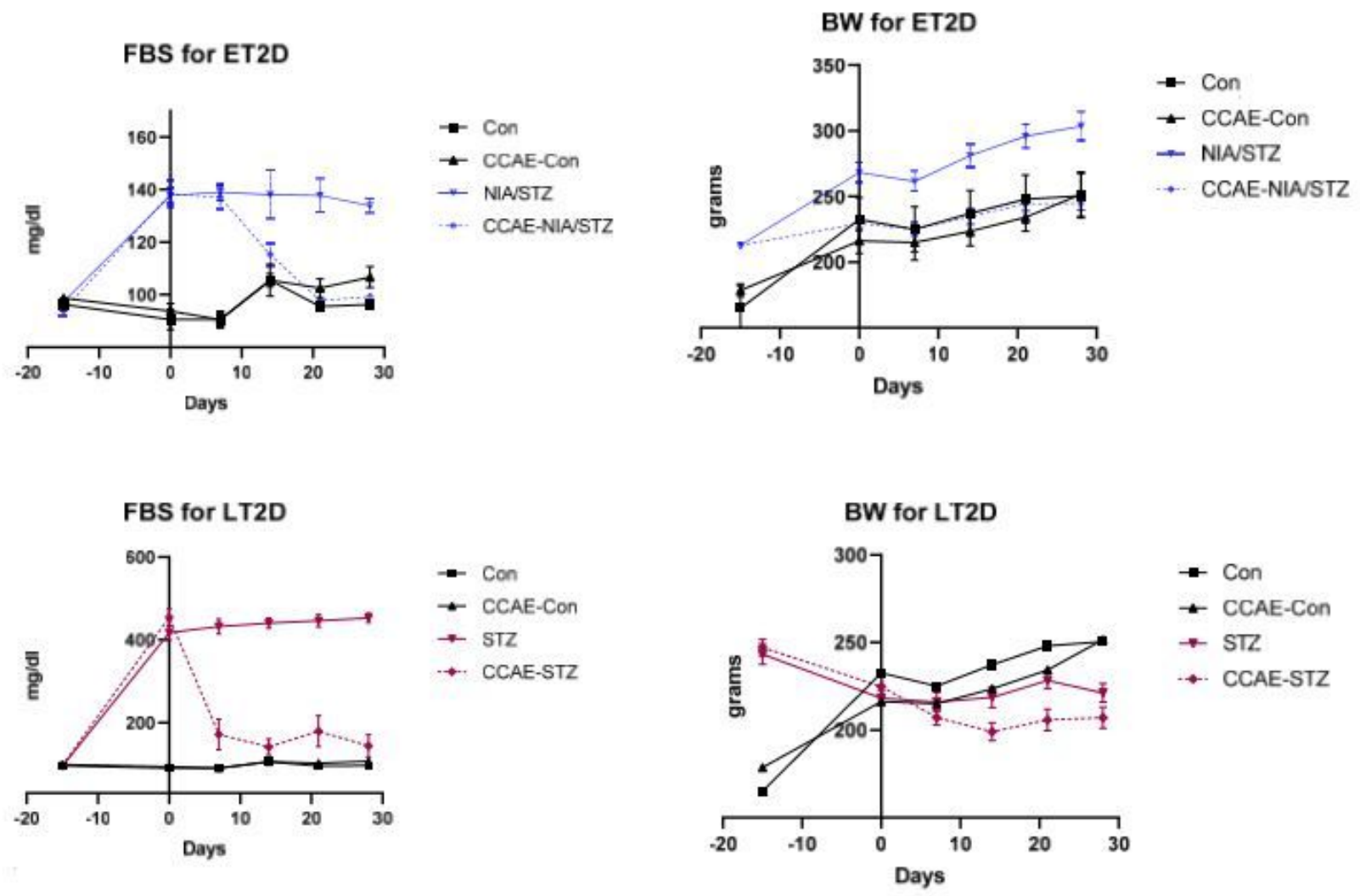

Figure 2

Weekly FBS and body weights. After diabetes induction (i.e., on day zero), FBS increased $₫ 0.44$ (44\%) and $₫ 3.5$ (352\%) times in NIA/STZ and STZ groups, respectively. By day 28, CCAE had lowered the FBS in both early (CCAE-NIA/STZ group, $133.8 \pm 7.9 \mathrm{mg} / \mathrm{dl}, \mathrm{p}=0.004 \mathrm{vs}$. NIA/STZ) and late (CCAE-STZ group, $453.0 \pm 41.7 \mathrm{mg} / \mathrm{dl}, \mathrm{p}=0.001 \mathrm{vs}$. STZ) diabetes groups to a value very close to Con ( $p=0.23$ for NIA/STZ group and $p=0.10$ for STZ group, vs. Con), a demonstration of the chronic or long-term hypoglycemic effect of CCAE in both early- and late-stage diabetes. On day 28, the body weights of the treated groups were not significantly different from their corresponding controls (Con vs, CCAE-Con, $p=1.0$; NIA/STZ vs. CCAE-NIA/STZ, $p=0.72$; STZ vs. NIA/STZ, $p=0.69$ ). Day “-15" indicates the starting day of diabetes induction by STZ or NIA/STZ injection; and day 0 , indicates the start of daily treatment with CCAE that lasted for 28 days. Con: non-diabetic control, CCAE-Con: non-diabetic control treated with CCAE, NIA/STZ: early-stage diabetic group, CCAE-NIA/STZ: the earlystage diabetic group treated with CCAE, STZ: late-stage diabetic group, CCAE-STZ: the late-stage diabetic group treated with CCAE. 


\section{C-Peptide}

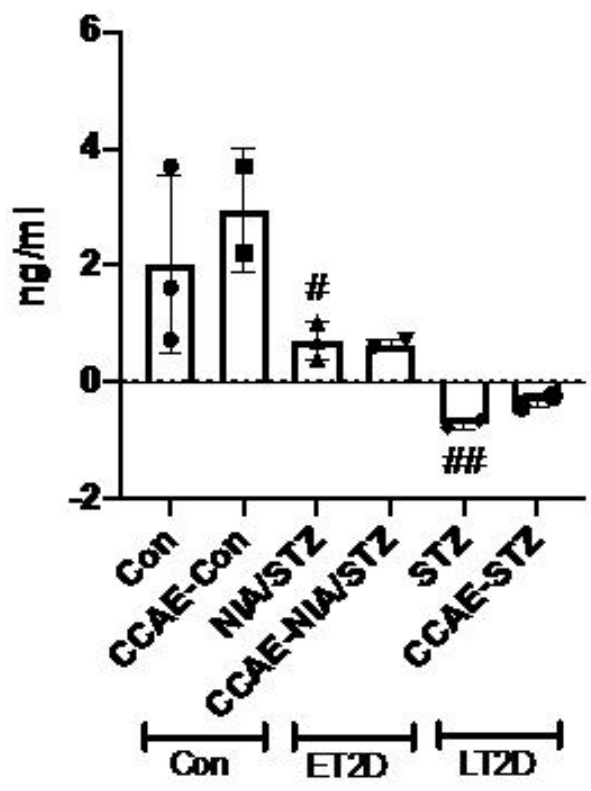

HbA1c

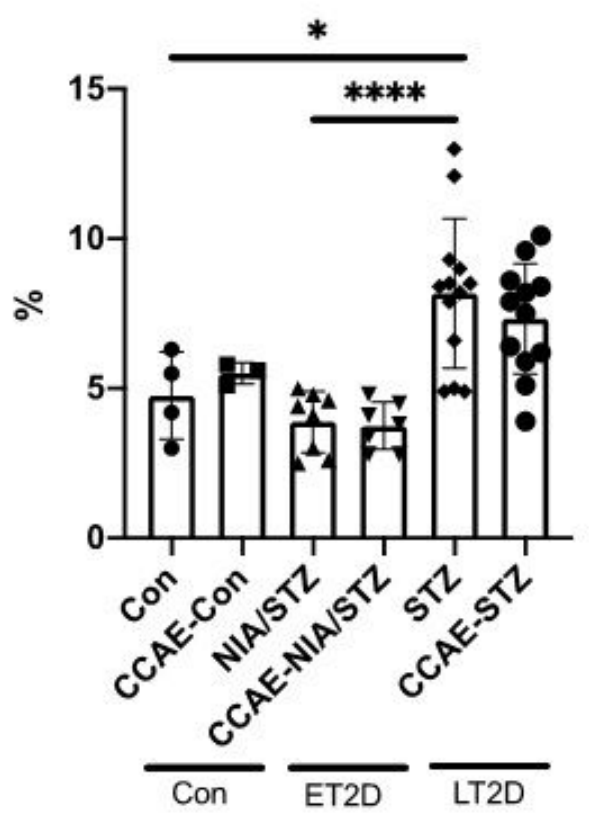

Figure 3

C-peptide and $\mathrm{HbA} 1 \mathrm{c}$ levels on day 28. C-peptide levels indicate that pancreatic $\beta$-cells were totally or partially destroyed in STZ- and NIA/STZ- rat groups, respectively, and that CCAE did not seem to increase insulin secretion from the remaining $\beta$ cells. HbA1C levels increased in diabetic groups; 28 days of treatment with CCAE did not produce any change in HbA1C levels of treated diabetic groups relative to untreated counterparts. Con: non-diabetic control, CCAE-Con: non-diabetic control treated with CCAE, NIA/STZ: early-stage diabetic group, CCAE-NIA/STZ: the early-stage diabetic group treated with CCAE, STZ: late-stage diabetic group, CCAE-STZ: the late-stage diabetic group treated with CCAE. *, $p<0.05 ; \uparrow, p=0.001$. 


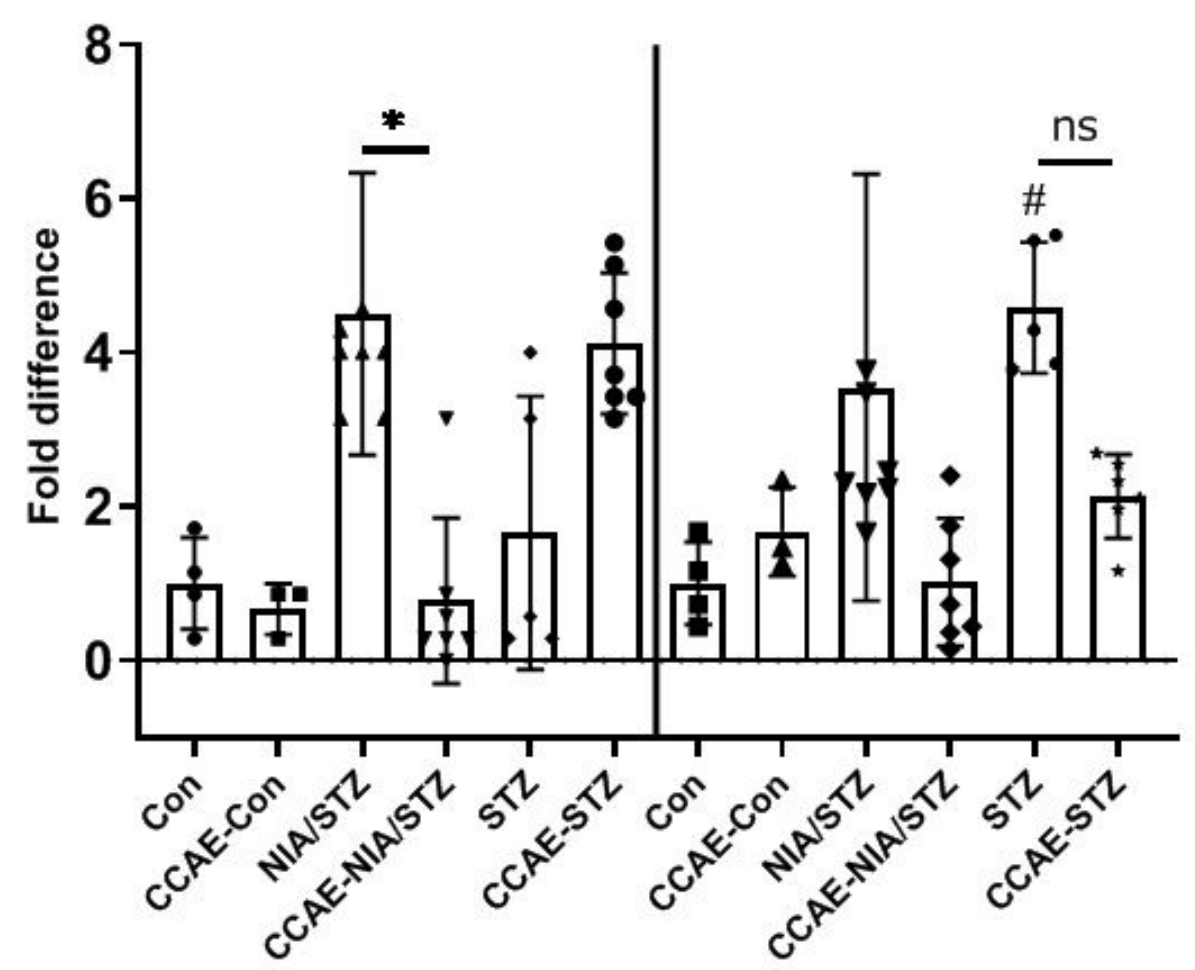

Figure 4

Effects of diabetes induction and CCAE treatment on hepatic gluconeogenesis. After diabetes induction, there was a significant rise in the mRNA levels of G6Pase and a slight rise of PEPCK in ET2D (NIA/STZ group) and treatment with CCAE (for 28 days) resulted in a small significant decrease in the expression of G6Pase. In LT2D, the expression of PEPCK increased significantly ( $\mathbb{1} 12$ folds) after induction of diabetes and decreased significantly after CCAE treatment. Con: nondiabetic control, CCAE-Con: non-diabetic control treated with CCAE, NIA/STZ: early-stage diabetic group, CCAE-NIA/STZ: the early-stage diabetic group treated with CCAE, STZ: late-stage diabetic group, CCAE-STZ: the late-stage diabetic group treated with CCAE. The variables were compared by non-parametric tests between independent samples followed by Mann-Whitney Test. Data are presented as the mean \pm SEM. **, $p<0.01 ; * \star *, p<0.001$. Every bar is the average of 2 duplicate analyses for all rats of all groups. 

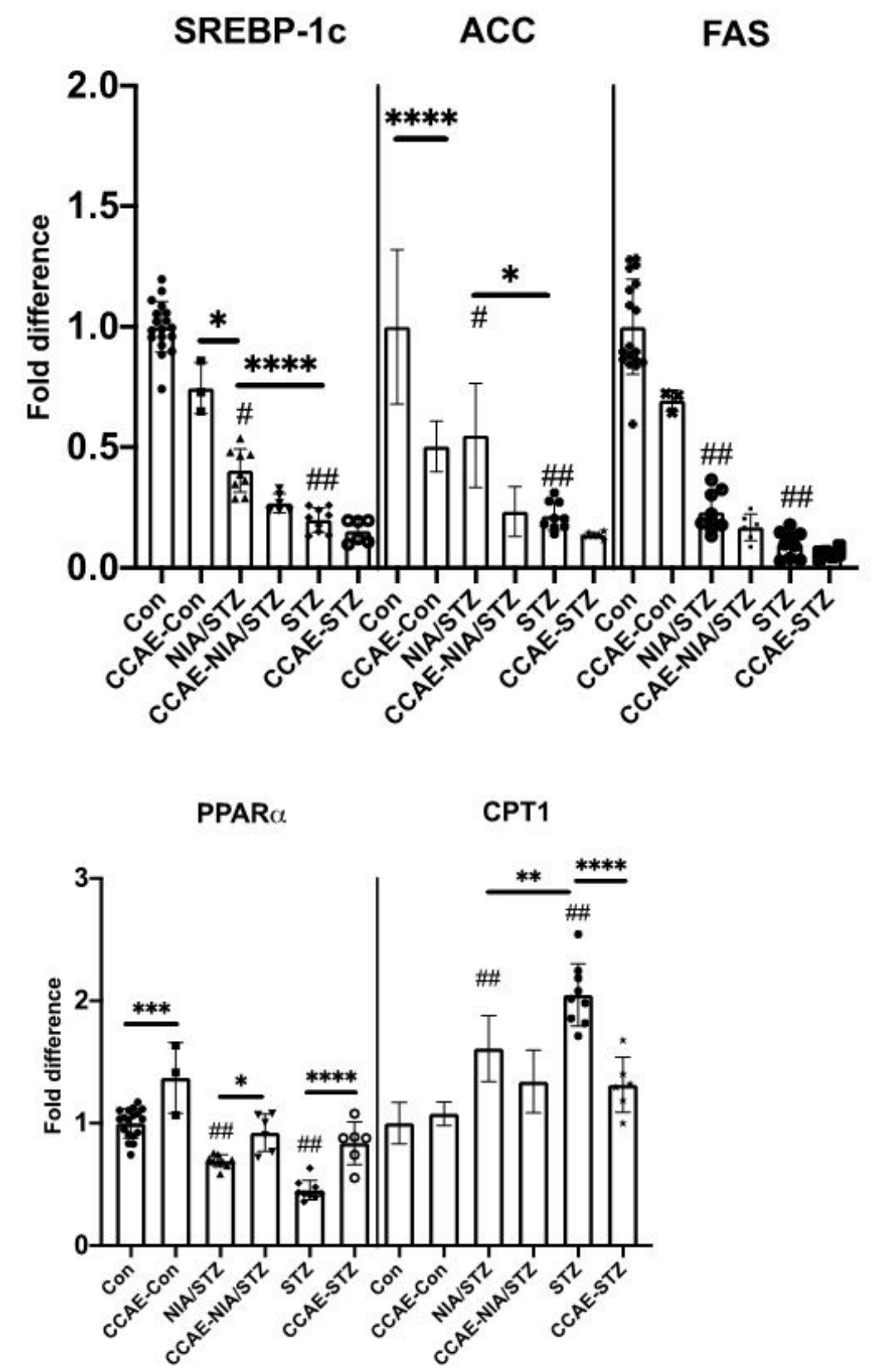

Figure 5

Effect of CCAE on lipogenesis and fatty acid oxidation pathways. Con: non-diabetic control, CCAE-Con: non-diabetic control treated with CCAE, NIA/STZ: early-stage diabetic group, CCAE-NIA/STZ: the early-stage diabetic group treated with CCAE, STZ: late-stage diabetic group, CCAE-STZ: the late-stage diabetic group treated with CCAE. ${ }^{*}<0.05 ;{ }^{* *} p<0.01 ; * \star *$ $\mathrm{p}<0.001$. Data are presented as the mean \pm SEM. 


\section{PCC in liver}
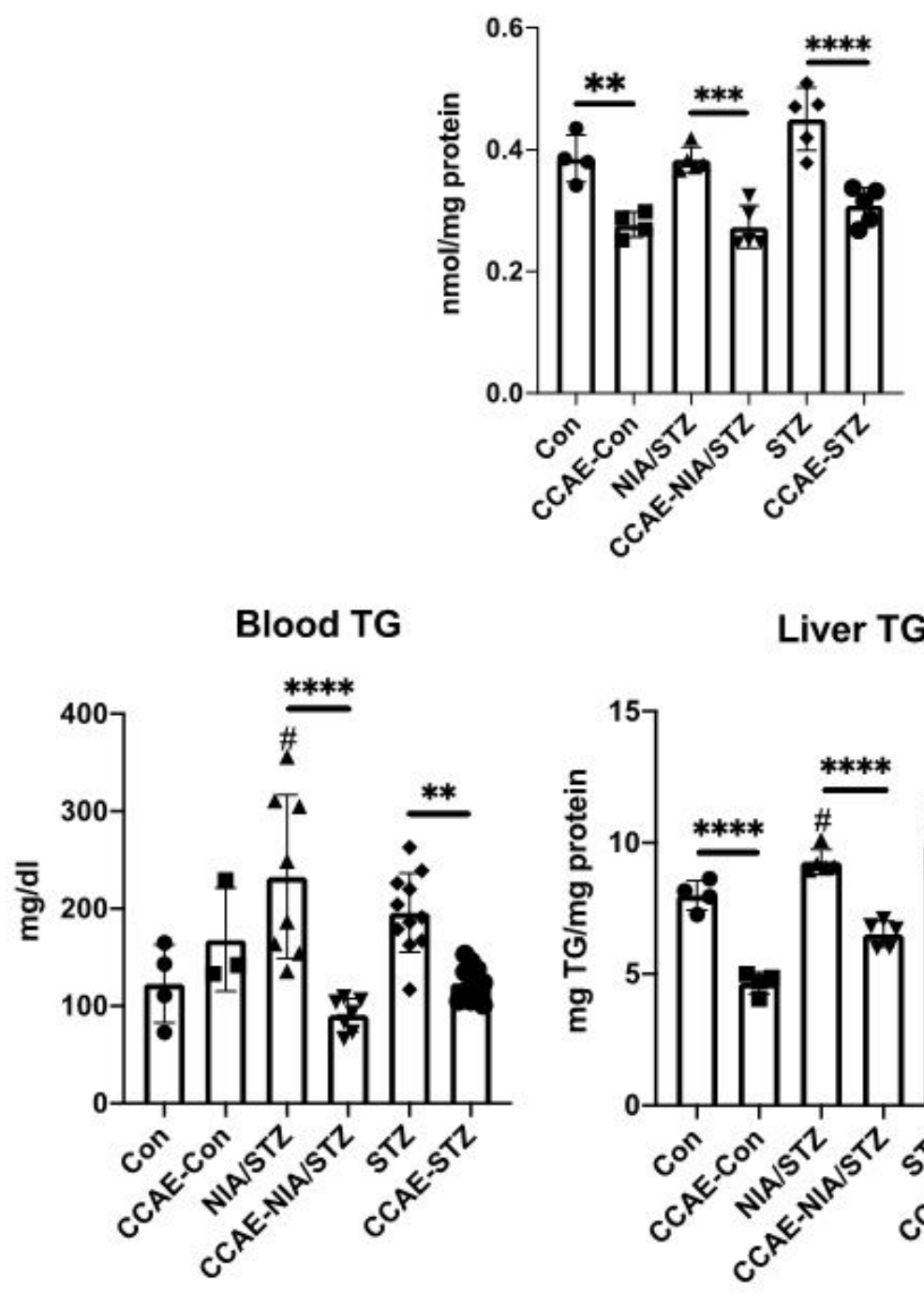

\section{Liver TG}

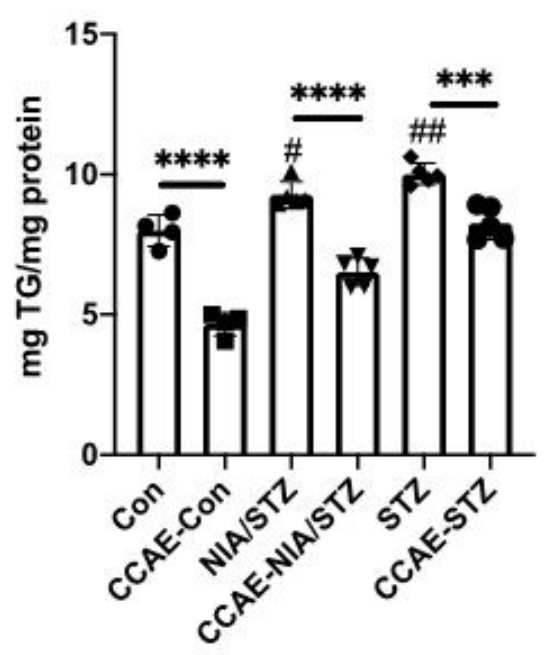

Figure 6

Effect of CCAE on hepatic protein carbonylation and triglyceride levels. Increased levels of PCC (LT2D and ET2D vs Con, $p=0.73$ and $p=0.19$, respectively) and TG were observed in the liver tissue of both diabetic groups compared to Con. Treatment with CCAE led to a significant reduction of both variables in all treated groups compared to their untreated controls. Con: non-diabetic control, CCAE-Con: non-diabetic control treated with CCAE, NIA/STZ: early-stage diabetic group, CCAE-NIA/STZ: the early-stage diabetic group treated with CCAE, STZ: late-stage diabetic group, CCAE-STZ: the late-stage diabetic group treated with CCAE. Values are expressed as mean \pm SEM. *, $p=0.016 ;{ }^{*}, p=0.008, \dagger, p=0.029$. 

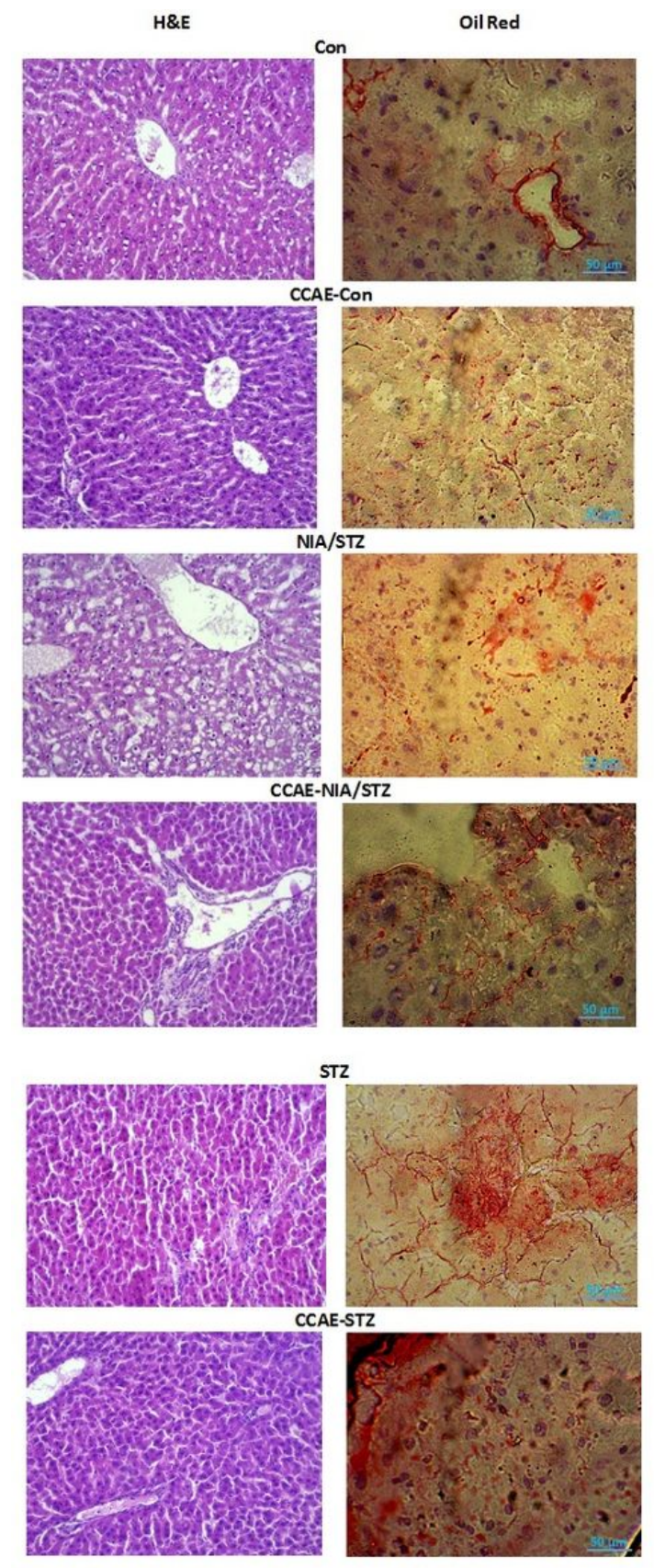

Figure 7

Effect of CCAE on liver histology. Liver histology was studied using H\&E and Oil Red O staining. According to H\&E, large macrovesicular LDs accumulated in the liver from early-stage T2D, which were eliminated by CCAE treatment. Lipid in LT2D liver was less notable perhaps due to its different (microvesicular) morphology. Fibrosis of the portal area and fibroblast accumulation in the liver were other remarkable manifestations in the late-stage diabetic liver tissues which seemed not to improve by CCAE treatment. Oil Red 0 staining approved that in diabetic livers, fat accumulated in greater extent and treatment with CCAE tended to decrease the hepatic fat. 


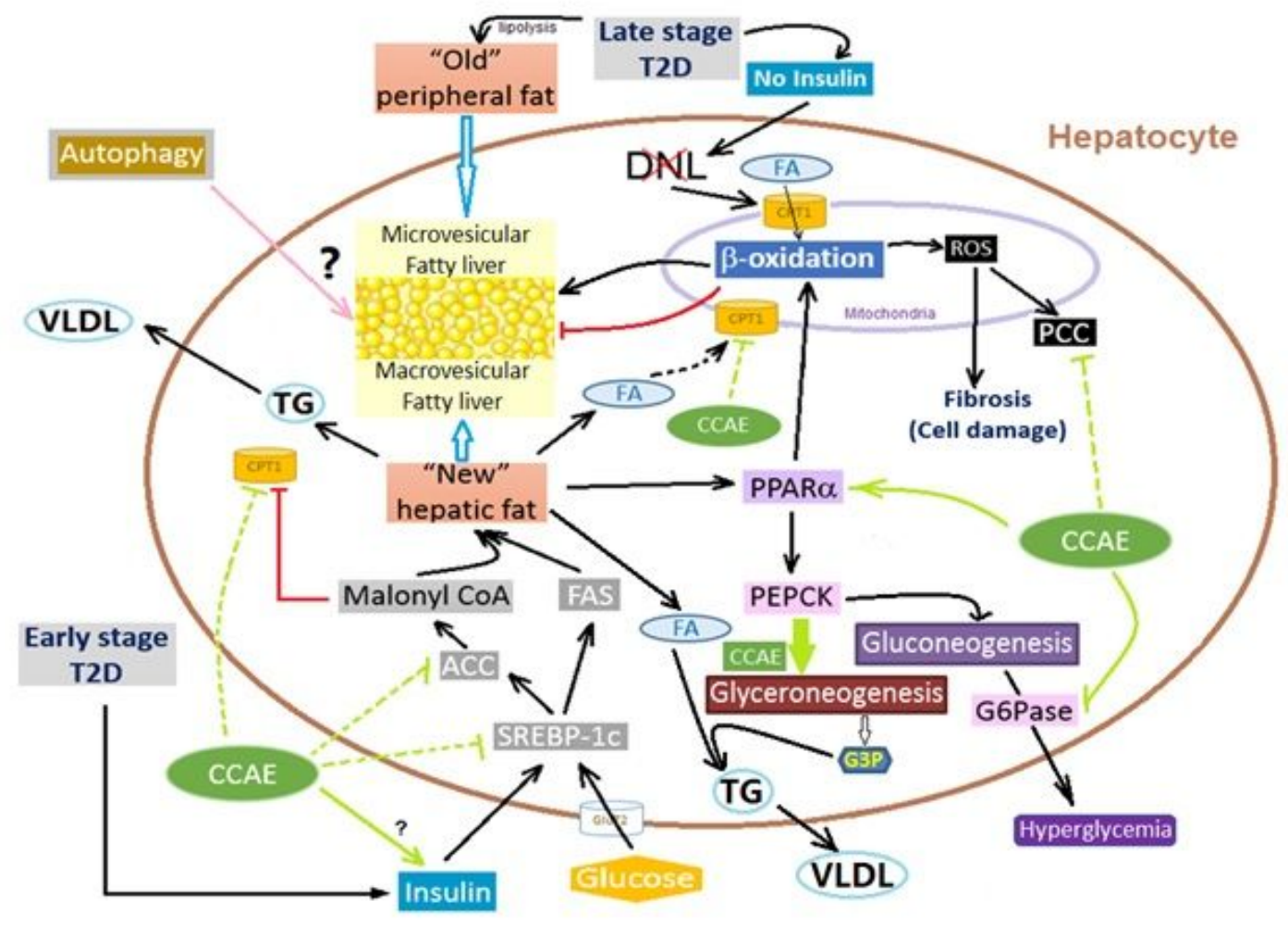

Figure 8

Schematic presentation of sugar and fat metabolism and the effect of CCAE. Low FA 囚-oxidation/disposal may give rise to the fatty liver when accompanied by increased DNL, as it may occur in ET2D. Enhanced 囚-oxidation of FAs should prevent fatty liver, unless the rate of FA entry into the liver overwhelms the capacity of the mitochondria, as it may occur in LT2D, when it may lead to mitochondrial dysfunction. The attenuation of free radical scavenging mechanisms would then lead to fatty liver, oxidative stress, fibrosis, and liver damage. Citrullus colocynthis aqueous seed extract (CCAE) was able to fight against hyperglycemia and fatty liver in many frontlines, including free radical scavenging and lowering ROS levels, inhibiting CPT1, activating the expression of PPARa, and directing PEPCK activity more towards glyceroneogenesis than towards gluconeogenesis. In addition to gluconeogenesis and glyceroneogenesis, another important function of PEPCK is to carry out cataplerosis, the removal of citric acid cycle intermediates to prevent their accumulation in mitochondrial matrix, which has not been shown [74].

\section{Supplementary Files}

This is a list of supplementary files associated with this preprint. Click to download.

- Supplement1.docx

- Supplement1.docx

- Supplement1.docx

- Supplement2.docx

- Supplement2.docx

- Supplement2.docx

- Supplement3.docx

- Supplement3.docx 
- Supplement3.docx

Page 25/25 